\title{
CHANGE OF THE WRITING-HAND: UNUSUAL MANIFESTATION OF HALLERVORDEN-SPATZ DISEASE
}

\author{
Omer Ć. Ibrahimagić ${ }^{1}$, Dževdet Smajlović ${ }^{1}$ Zikrija Dostović ${ }^{1}$, Svjetlana Mujagić ${ }^{2}$, \\ Zejneba Pašić ${ }^{1} \&$ Denisa Salihović ${ }^{1}$ \\ ${ }^{I}$ Department of Neurology, University Clinical Centre Tuzla, Tuzla, Bosnia and Herzegovina \\ ${ }^{2}$ Department of Radiology and Nuclear Medicine, University Clinical Centre Tuzla, Tuzla, Bosnia and Herzegovina
}

received: 10.2.2017;

revised: 15.5.2017;

accepted: 19.6.2017

$* * * * *$

\section{INTRODUCTION}

Hallervorden-Spatz disease (HSD) is a rare neurodegeneration with accumulation of iron in basal ganglia, dystonia, dysarthria, rigidity, and choreoathetosis. Syndrome may present in childhood and progress relentlessly culminating in early death (classical HSD) or in second or third decade with slow progression (atypical HSD) (Hayflick et al. 2003). Magnetic resonance imaging (MRI) appearance in HSD, revealing bilaterally symmetrical, hyperintense signal changes in the anterior medial globus pallidus, with surrounding hypointensity in the globus pallidus, on T2-weighted scanning. These features are fairly diagnostic of HSD and have been termed the ,eye of the tiger" sign (Dashti \& Chitsaz 2014). Unfortunately, exact etiology, predictors, and biochemical markers are not known.

\section{CASE REPORT}

We presented 17 years old Caucasian right-handed female with history of different symptoms/signs at least 24 months before admission. Her parents were nonconsanguineous, birth was at full-term and uneventful. There was no delay in attaining the developmental milestones. In early childhood, she often expressed stubborness as well as two syncopas despite of standing for a long time, without proper meal before. She was a $\mathrm{C}$ - average pupil, without nicotin, alcohol and drug abuse. Menstruations were on time, normal, lasted for 4 - 5 days. Except correction of visual acuity, her health condition was good till the age of 15 years when she unexpectedly changed dominant right writinghand, without writer's cramp or any other complains before. Members of her family were really surprised. She continued to write with left hand and use right hand for everyday tasks. In next 6 months, from time to time, she became nervous, verbally aggressive, sometimes with destruction of house stuff. During free time, she often stayed at home and avoided going out. Even 20 months after change of dominant right writing-hand, young girl expressed stiffness and athetoid involuntary movement, like bending of right hand in fingers and wrist. She felt reliefed after her fingers were straightened, but only for a short period of time after that maneuver. She also felt mild difficulties in speaking. Physical activity, exercises and situations full of tense behaviour maked involuntary movements even worse. Abnormal movements subsided during sleep. Except some periodical problems with discrete movements of toes at mother's brother and mother's uncle, family history was not significant.

Neurological examination revealed an average built young girl, without dystonic posturing of trunk, head, and neck as well as oromandibular dystonia. Right-hand writing was unreadable, unlike the left-handed one. She exhibited mild rigidity of upper limbs with Negro's phenomenon on the right, dystonic movements in right hand / rarely in right toe (plantar flexion), discrete postural / kinetic tremor, reduction of synkinetic rightarm movements, exaggerated tendon jerks and mild speech-dysarthria. No problems of chewing, motility of face or bradikynesia were seen, also there was not obvious difficulties in walking except periodical movement of right hand behind her back. Routine laboratory evaluation including caeruloplasmin, ferritin, iron, coper, lipid profile, and antinuclear antibodies were within normal ranges. Peripheral-blood film did not reveal acanthocytes. Dopler-sonography of brain parenchyma was normal, and fundus examination was unremarkable, without Kayser-Fleischer's ring due to slit-lamp test. Unfortunately, analysis to detect PANK 2 gene mutation could not be done in our country. Cognitive examinations showed average results, without progressive intellectual decline. Direct psychological interview/exploration showed impulsive behaviour, unpatience and decrease in perception of reality, fear of social contacts, plane moral control, and moderate anxiety.

Diagnosis of HSD, based on the neurological symptoms/signs, absence of Wilson's disease, acaeruloplasminemia and neuroferritinopathy as well as MRI findings, was made. Our patient was given levodopa/ carbidopa combination (62.5 mg orally, b.i.d.) After two-months follow up, she has been satisfied with her condition, also shown discrete improvement of rigidity, dystonia, and tremor without further deterioration in psychological changes and speech. 

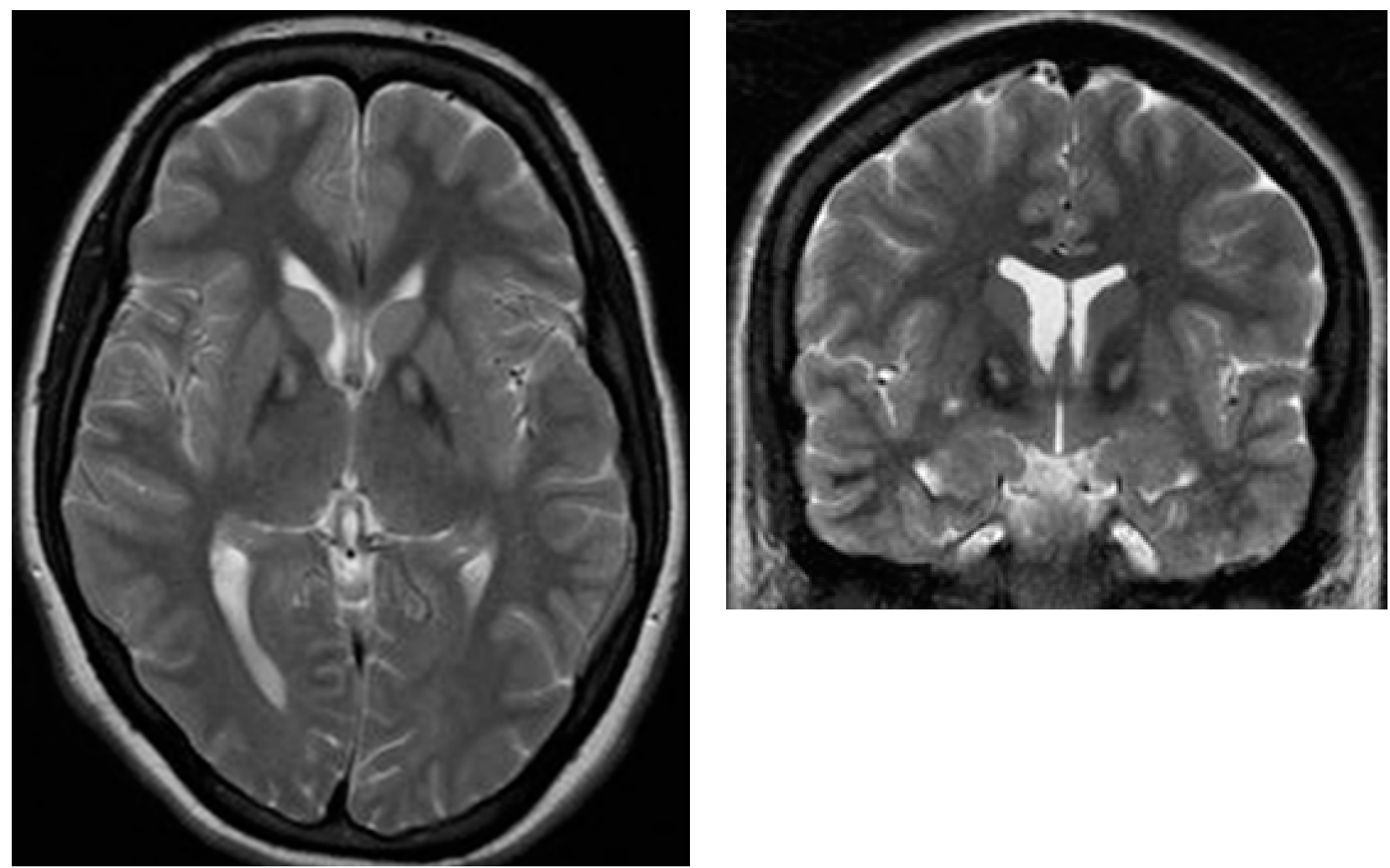

Figure 1a,b. Axial and coronal $\mathrm{T} 2 \mathrm{~W}$ images (1.5 Tesla) show hypointense in globus pallidus with symmetric hyperintense foci located anteromedially - „eye of the tiger“ sign

\section{DISCUSSION}

This brain iron accumulation was first reported in 1922 by Julius Hallervorden and Hugo Spatz - German neuropathologists. Unfortunately, they conducted unethical studies on brain specimens of mentally handicapped persons, executed during third Reich euthanasia program in the context of "Racial Hygiene" (Shevel 1992).

HSD is a rare disease included under the broad category ,neurodegeneration with brain iron accumulation" (NBIA) along with acaeruloplasminemia and neuroferritinopathy. The latter two may have similar neurological features, but can be distinguished from HSD by later onset during adulthood, MRI findings, laboratory tests (undetectable serum caeruloplasmin, low serum iron and elevated serum ferritin in acaeruloplasminemia / low serum ferritin in men and postmenopausal women in neuroferritinopathy), and genetic analysis (Tonekaboni \& Mollamohammadi 2014, Vinod et al. 2011). Initially, hyperintense areas are seen at the globus pallidus and substantia nigra. Later, as the HSD progresses, a hypointense rim is seen around it, due to iron deposition. Evolution of HSD suggests that neuroaxonal degeneration is followed by pallido-nigral pigmentation and deposition which is only a late phenomenon Gallucci et al. 1990). The characteristic MRI findings corresponds to pathological findings. Sethi et al described changes as the „eye of the tiger“ sign as we seen in our patient (Sethi et al. 1988).
Average survival after diagnosis is about 12 years (Sharma et al. 2005, Swaiman 2001). The progression of atypical HSD to loss of independent ambulation is reported to be slower (over 15-40 years from onset), but rapid progression (within 4 years) has been rarely described. Gregory et al. 2009, Hickman et al. 2001). However, since the first description of HSD, little progress has been made in the treatment, so there isn't proper help. Genetic analysis could not be done in our state, so it was objective limitation. We think that change of dominant writing-hand could be early manifestation of HSD, psychological or organic, before obvious clinical and neuroradiological findings. Surprisingly, at the end of the August 2016, there weren't any data (PUBMED search) of associate HSD with changes of the writing-hand (key words: HallervordenSpatz disease, (Change of) Writing-hand or Dystonia, (Change of) Writing-hand). There were only four literature references due to search with key words: Hallervorden-Spatz disease, Writing or HallervordenSpatz disease, Writing-Dystonia, without any potential data of change within the writing-hand in patients with HSD (Lechner et al. 1999, Guimarães \& Santos 1999, Garcia-Ruiz et al. 2015, Zhang et al. 2005). Due to best of author knowledge, our single experience, and literature survey, we presume that this unusual manifestation may have association with future development of HSD. At the end, we suggested that change of writing-hand should be kept in mind and considered at clinical follow-up in future. 


\section{Acknowledgements:}

Informed consent was obtained from the patient's mother.

Conflict of interest: None to declare.

\section{Contribution of individual authors:}

Conception, design and literature searches: Omer Ć. Ibrahimagić;

Data collecting: Omer Ć. Ibrahimagić, Svjetlana Mujagić;

Drafting the article: Omer Ć. Ibrahimagić;

Critical revision of the manuscript for important intellectual content: Dževdet Smajlović, Zikrija Dostović, Zejneba Pašić, Denisa Salihović.

\section{References}

1. Dashti M \& Chitsaz A: Hallervorden-Spatz disease. Adv Biomed Res 2014; 3:191.

2. Gallucci M, Cadona $F \&$ Arachi M: Follow up MR studies in Hallervorden Spatz disease. J Comput Assist Tomography 1990; 14:118-20.

3. Garcia-Ruiz PJ, Ayerbe J, Vela Desojo L, Feliz CE \& Del Val Fernandez J: Deep brain stimulation for pantothenate kinase-associated neurodegeneration. Case Rep Neurol Med 2015; 245735. doi: 10.1155/2015/245735. Еpub $2015 \mathrm{Feb} 23$.

4. Gregory A, Polster BJ \& Hayflick SJ: Clinical and genetic delineation of neurodegeneration with brain iron accumulation. J Med Genet 2009; 46:73-80.
5. Guimarães $J$ \& Santos JV: Generalized freezing in Hallervorden-Spatz syndrome: case report. Eur J Neurol 1999; 6:509-13.

6. Hayflick SJ, Westaway SK, Levinson B, Zhou B, Johnson $M A$, Ching KH, et al.: Genetic, clinical, and radiographic delineation of Hallervorden-Spatz syndrome. $N$ Engl $J$ Med 2003; 348:33-40.

7. Hickman SJ, Ward NS, Surtees RA, Stevens JM \& Farmer SF: How broad is the phenotype of Hallervorden-Spatz disease? Acta Neurol Scand 2001; 103:201-3.

8. Lechner C, Meisenzahl EM, Uhlemann H, Helber-Böhlen H \& Fähndrich E: Hallervorden-Spatz syndrome. Differential diagnosis of early onset dementia. Nervenarzt 1999; 70:471-5.

9. Sethi KD, Adams RJ, Loring DW \& El Gammal T: Hallervorden Spatz disease: clinical and MRI correlations. Ann Neurol 1988; 24:692-4.

10. Sharma MC, Aggarwal N, Bihari N, Goyal V, Gaikwed S, Vaishya $S$ et al.: Hallervorden Spatz disease: MR and pathological findings of a rare case. Neurol India 2005; 53:102-4.

11. Shevell M: Racial hygiene, active euthanasia and Julius Hallervorden. Neurology 1992; 42:2214-9.

12. Swaiman KF: Hallervorden-Spatz syndrome. Paediatr Neurol 2001; 25:102-8.

13. Tonekaboni SH \& Mollamohammadi M: Neurodegeneration with brain iron accumulation: An overview. Iran $J$ Child Neurol 2014; 8:1-8.

14. Vinod K, Giridharan $S$ \& Dutta T: Hallervorden-Spatz syndrome: a rare cause of extrapyramidal manifestations. Ann Neurosci 2011; 18:133-5.

15. Zhang YH, Tang BS, Zhao AL, Xia K, Long ZG, Guo JF et al.: Novel compound heterozygous mutations in the PANK 2 gene in a Chinese patient with atypical pantothenate kinaseassociated neurodegeneration. Mov Disord 2005; 20:819-21.

Correspondence:

Omer Ć. Ibrahimagić, $M D$

Department of Neurology, University Clinical Centre Tuzla

Šetalište Slana banja Street 4/1, 75000 Tuzla, Bosnia and Herzegovina

E-mail: omeribrahimagic@yahoo.com 